\title{
NEVUS PIGMENTADO DE JUNÇÃO
}

\author{
Silvina Terezinha Lima Grossi \\ Professôra Assistente do Departa- \\ mento de Cirurgia e Ortopedia \\ Hugo Gigante \\ Odontolando 1969 \\ Ciro Faccini \\ Odontolando 1969
}

\section{SIYOPSE}

Classificação dos Nevus Pigmentados, e relato de um caso de NEVUS PIGMENTADO DE JUNÇ̃̃o, em paciente de 16 anos, do sexo feminino e de côr prêta, localizado na mucosa interna do lábio 'superior esquerdo.

\section{CONSIDERACÕES GERAIS}

o Nevus Pigmentado é má formação do tipo, geralmente tumoral e cutâneo, raramente encontra-se localizado nas mucosas. E constituído por células névicas de origem discutida (1), se epiteliais afirmada por UNNA ou se neurais segundo FEYRTER (4). Sugerem outros a origem neuro-epitelial. As células névicas podem ou não apresentar pigmentação melanínica em seu citoplasma (1).

O Nevus Pigmentado por ser assintomático e pequeno, passa desapercebido, diminuindo os ralatos na literatura (2).

As possíveis variações metaplásicas a que o nevus está sujeito leva ao cirurgião, a um cuidado especial na escolha da técnica, que sempre deverá ser radical (6).

\section{Classificag̃̃̃O}

Existem várias e discutidas Classificações para os Nevus Pigmentados, sugerimos a de Lever (3) por nos parecer a de maior acertiva. 
Considera o autor dois tipos de nevus:

$$
\begin{aligned}
& 1 \text { - INTRADÉRMICO } \\
& 2 \text { - DE JUNÇÃO }
\end{aligned}
$$

INTRADẼRMICO: - 0 NevUS dêste tipo caracteriza-se por suas células disporem-se em ninhos ou cordões, circundada, por feixes de colágeno. No tecido conjuntivo fibroso, as células névicas encontramse mais afastadas tendo a forma de fuso. O epitélio poderá apresentar-se normal, sendo que algumas vêzes encontra-se achatado devido a pressão do tumor (5). Em alguns casos são vistas hiperceratose e papilose, sendo que o crescimento se faz em forma de laços, dando êste origem ao NEVUS Pigmentado Verrugoso. Quando da presença de pelos recebe a classificação de NEVUS PIGMENTADO PILOSO. O Nevus intradérmico é de ocorrência mais freqüente, apresentando-se plano ou pediculado, situa-se em qualquer região da cavidade oral sendo a de maior freqüência - gengiva, lábios e palato (1).

DE JUNÇÃO: - O Nevus Pigmentado de Junção apresenta suas células localizadas abaixo do tecido epitelial, sendo de prognóstico mais sombrio, as transformações malignas são de maior índice que o anterior. A ocorrência na cavidade oral é bastante rara (1). Esta forma de Nevus foi bem descrita por Ebert e por Traub e Keil, em que afiançam ser o Nevus de Junção de conșiderável atividade de fuga na junção derme epiderme. A camada basal é geralmente muito pigmentada. Há grandes ninhos de células que se projetam para dentro do corium, estando assim no estágio de fuga. Não há infłltrado inflamatório. Em raras circunstâncias, as células que compõem os ninhos intradérmi$\cos$ e subdérmicos são fusiformes e dotadas de estroma, assemelhandose mais às células de Schwann do que as células epidérmicas. Os ninhos de células assemelham-se aos corpúsculos tácteis de Missner. Os Nevus de Junção são potencialmente malignos, daí a denominação de «nevus ativos» para êstes e de «inativos» para os intradérmicos. São encontradas as denominações de Melanomas benignos para os intradérmicos e de Melanomas Malignos para os de junção (4). Consideram outros uma terceira classificação que é a de pevus composto (7) sendo um tipo com características de ambos.

\section{CASO CLfNico}

Paciente: E.R.

Sexo: feminino

Idade: 26 anos

Côr: prêta

Profissão: doméstica

Nacionalidade: brasileira

Naturalidade: Santa Catarina

Motivo da consulta: Extrações dentárias

Exame clínico: Visível massa tumoral, de tamanho de um grão de arroz localizada na mucosa interna do lábio superior esquerdo. Consistência: mole. Não apresentava dor. Processo de mais ou menos 10 anos, 
sem apresentar crescimento apreciárel. Ausência de reação ganglionar.

Diagnãstico clínico: Nevus Pigmentado.

Pré-operatório: Anamnese - normal. Estado geral do paciente Bom.

Trans-operatório: Preparo do paciente. Antissepsia oral com mertiolato. Anestesia terminal submucosa. Incisição: fusiforme distando $3 \mathrm{~mm}$ da lesão em superfície, e $5 \mathrm{~mm}$ em profundidade. A exérese da peça foi feita mediante pinças Allis. Hemostasia por laqueamento. Sutura interrompida, com fio de sêda 000 .

Pós-operatório: Prescrição medicamentosa - Analgésico: Anador, sendo um comprimido de $6 \mathrm{~h} / 6 \mathrm{~h}$. Aplicação de gêlo nas 24 primeiras horas. Remoção da sutura, 8 dias após. Cliente passando muito bem. Até o presente momento não há qualquer início de recidiva.

Exame histopatológico: Laudo $\mathrm{n}^{\mathrm{Q}}$ 3042 .

Diagnóstico: NEVUS PIGMENTADO DE JUNÇÃO

Assinado - Hardy Ebling

\section{SYNOPSIS}

This paper presents besides con. cept and classification of Pigmented Nevus, a case report of a patient with Junctional Pigmented Nevus, localized in the internal mucous of left upper lip. The patient is a 26 - years - old black woman.

\section{REFERÊNCIAS BIBLIOGRÁFICAS}

1. SHAFER, William G. Patologia bucal. Buenos Aires, Mundi, 1959. p. $68-70$.

2. KING, O. H. Jr. et alii. The frequency of pigmented nevi en the oral cavity.; report of five cases. Oral Surgery, Oral Medicine, and Oral Pathology, 23:82-90, jan. 1967.

3. LEVER, Walter F. M. D. Histopatology of the skin; melatomas. 3. ed. Philadelphia, Lppincott Company, 1949. p. 391.

4. ESTELLER, Arturo Pacios G. Nevus y melanoma facial. Boletin de Information Dentai, Madrid, $189: 347-348$, jul.-ago., 1963.

5. THOMAS, E. Comerford Jr. et alii. Nevus of the oral cavity. Oral Surgery, Oral Medicine and Oral Pathology, St. Louis, 17:148-151, jan.-jun., 1963.

6. SOHN, D. M. et alii. Pigmented nevus of the oral mucosa; report of a case. Journal of the American Dental Association, Chicago, 72:895-898, apr. 1966 . 


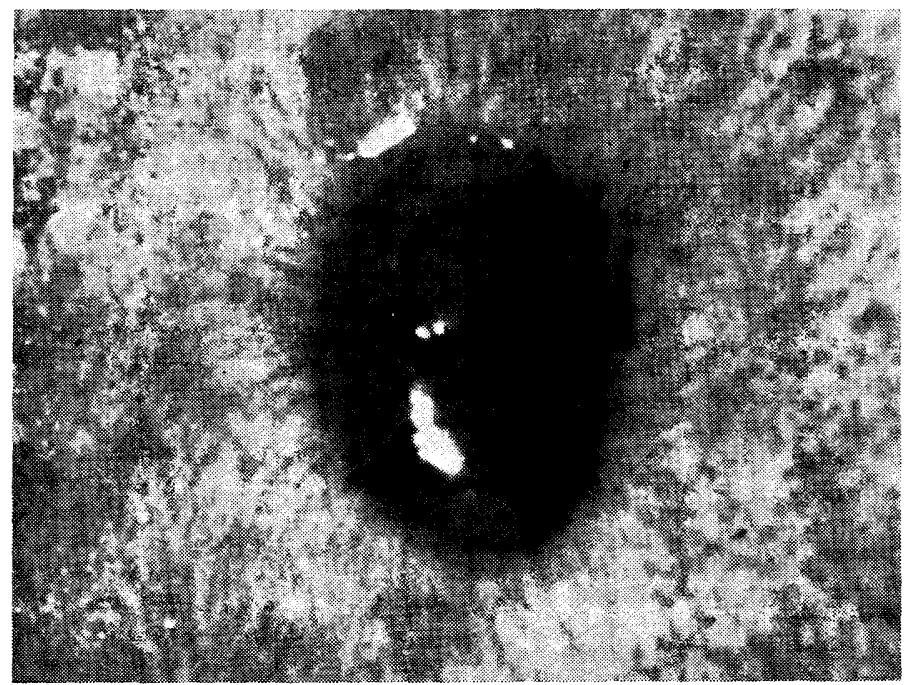

Foto 1 -

Aspecto macroscópico da lesão.

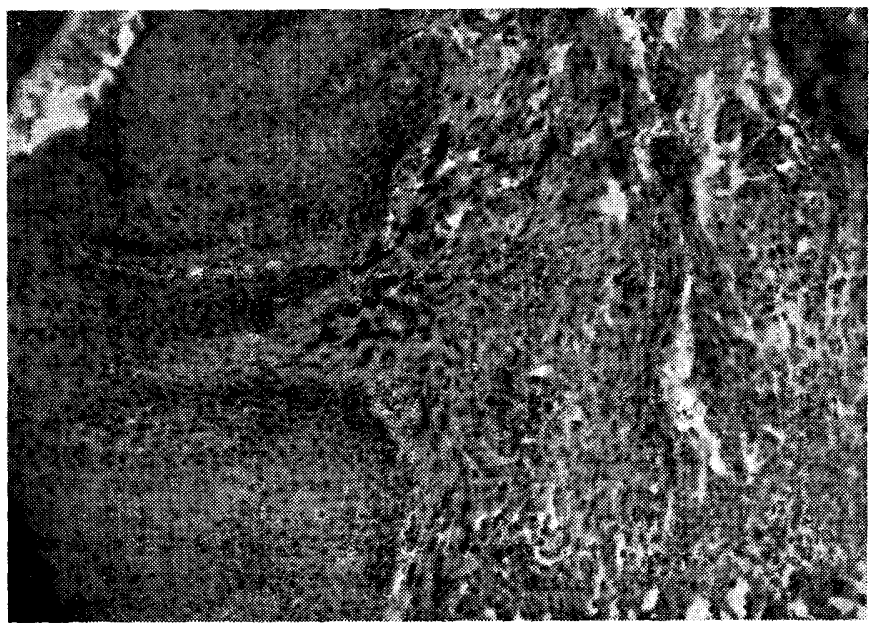

Foto 2 -

Epitélio com acantose. Células névicas na lâmina própria. Não há reação inflamatória. Aumento mais ou menos $100 \%$.

R. Fac. Odont. P. A. 10/11: $13-17,1968 / 1969$ 


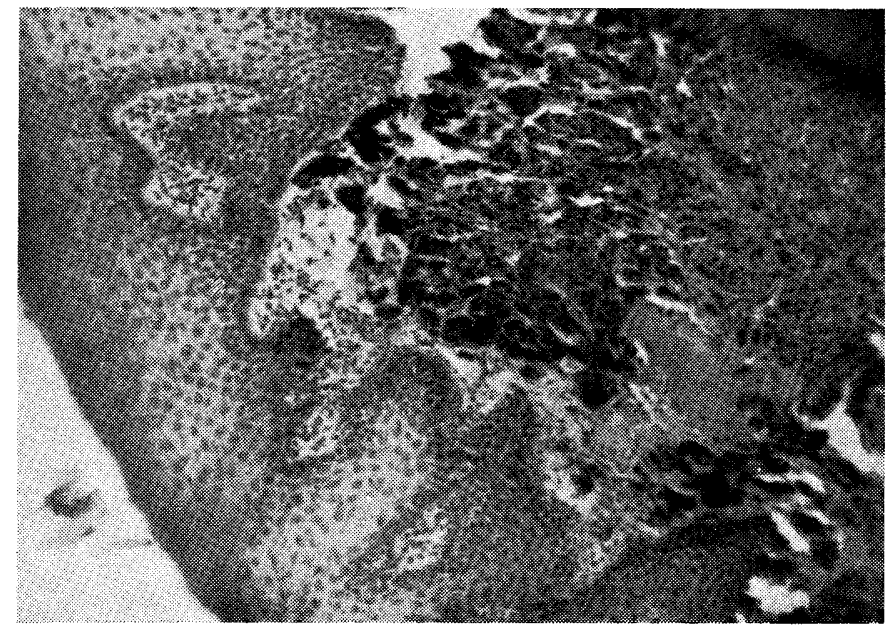

Foto 3

Aspécto histopatológico em maior aumento. Células névicas em ninhos num conjuntivo bastante celular e fortemente pigmentados. 